\title{
LOS MAESTROS DE PRIMERAS LETRAS EN LA RIOJA A MEDIADOS DEL SIGLO XVIII
}

\author{
José Luis Gómez Urdáñez \\ Universidad de La Rioja \\ jose-luis.gomez@unirioja.es \\ Nuria Pascual Bellido \\ Universidad de La Rioja \\ nuria-esther.pascual@unirioja.es
}

Jonathan Alvarez Arias, Julen Bermúdez Sarasola, David Frías Anzuola, Mikel García Benito, Juan Pedro Pedroarena Espinal, Pablo Pérez de Felipe, Mario Sáenz Martínez, Unai Salinas Barandiaran, Javier Zúñiga Crespo ${ }^{1}$

RESUMEN: Mostramos en este artículo la realidad del magisterio en La Rioja a mediados del siglo XVIII basándonos en el catastro de Ensenada y en documentos de la sección judicial del Archivo Histórico Provincial de La Rioja (AHPLR), fuentes que nos permiten comprobar que los maestros de primeras letras gozaban en La Rioja de una situación muy favorable y que su condición de servicio público necesario era aceptada ya en todos los pueblos. Pagados por los concejos y los padres -las dos fuentes de ingresos que recogió la ley Moyano de 1857-, los maestros gozaban de prestigio, desempeñaban oficios como organista, sacristán o incluso notario, y en general, disfrutaban de una buena situación económica relativa, siempre en el terreno de la austeridad obligada, pero muy por encima de la sociedad campesina en que se asentaban.

1. Universidad de La Rioja. Los autores son profesor y alumnos del curso Metodología de Historia Moderna (2017-2018), junto con la profesora Nuria Pascual, que se ha encargado de la cartografía, con la ayuda de Javier Zúñiga Crespo. La directora del archivo, Micaela Pérez, ha sido siempre la orientadora del trabajo, que se ha desarrollado en el Archivo Histórico Provincial de La Rioja (AHPLR). 
Palabras clave: maestro de primeras letras, catastro de Ensenada, ley Moyano, historia del magisterio, historia de la educación de niños, historia de la educación de niñas.

\section{PRIMARY SCHOOL TEACHERS IN LA RIOJA DURING MID-XVIII CENTURY}

ABSTRACT: This paper shows the reality of teaching in La Rioja in the mideighteenth century based on the Catastro of Ensenada and documents of the judicial section of the Provincial Historical Archive (AHPLR), sources that allowed us to verify that the literacy teachers enjoyed in La Rioja a very favorable situation and that their condition of necessary public service was accepted in all the towns. Paid by the councils and the parents -the two sources of income contained in the Moyano law of 1857- teachers enjoyed prestige, performed as organists, sacristans or even notaries, and in general, enjoyed a relatively good economic situation, always in the realm of forced austerity, but far above of the peasant society in which they settled.

Keywords: Literacy teacher, Catastro of Ensenada, Moyano law, history of teaching, history of children's education, history of girls' education.

Recibido: 19 de septiembre de 2018

Aceptado: 10 de abril de 2019

\section{Introducción}

Los esfuerzos del magisterio por dignificar su profesión han mantenido una relación dialéctica con la percepción social de la necesidad de la instrucción desde que el que enseñaba dejó de ser imagen del "Divino maestro" y la escuela fue algo más que la prolongación del lema evangélico "enseñar al que no sabe", es decir, desde que la secularización fue dando forma a la figura del maestro público, el maestro de primeras letras, cuyo trabajo era en parte costeado también públicamente. Muchos pueblos castellanos tuvieron ese maestro ya en el siglo XVI y su salario siguió siendo asumido por el concejo-como el del médico, el boticario, o el cirujano- hasta que lo encontramos en el siglo XVIII casi en las mismas condiciones, no tan mal pagado como se ha dicho si comparamos su situación con la del mundo en que vive, pues a menudo ejerce otra profesión y complementa sus ingresos, a los que también se añade lo que percibe de los padres de los escolares. Obviamente, las crisis de cosechas le afectaban como a todos sus vecinos, pues cuando los ayuntamientos y los padres veían disminuir sus ingresos los del maestro también se resentían. No es raro, por eso, encontrar en la documentación deudas y súplicas de pagos de atrasos, lo que se mantuvo, o incluso aumentó, en el XIX dando lugar a la leyenda del hambre del maestro de escuela, que es muy vieja. Ya en 1646, un 
alumno de Pedro Ruiz decía que su maestro "murió en suma pobreza, que es plaga común de los que enseñan letras no morir ricos". ${ }^{2}$ Pero como veremos, en La Rioja, la media de ingresos del maestro se situaba entre los 900 y los 1.000 reales, que no es una mala renta si pensamos en los muchos jornaleros que no ganaban ni la mitad. Con todo, encontramos a maestros muy mal pagados, por ejemplo el de Los Molinos de Ocón, Diego Pisón, que además era notario, "fiel de fechos" y sacristán, y que solo tenía una renta anual total de unos 500 reales. Don Diego hizo en su memorial para el catastro una velada crítica de su situación, pues eso era lo único que ganaba y eso era "de lo que nos hemos de alimentar, vestir, calzar y pagar médico, boticario y cirujano"3. No lo decía, pero los oficios que citaba estaban todos mejor pagado que el suyo (y lo siguieron estando hasta nuestros días).

La importancia del maestro era ya incontestable en el siglo XVIII y los concejos incluían su salario entre los gastos corrientes, como descubre el catastro que ordenó hacer en las 22 provincias de Castilla el marqués de la Ensenada a partir de 1749, y que ha servido de fundamento a nuestro trabajo ${ }^{4}$. Es bien sabido que las "respuestas generales" al interrogatorio de 40 preguntas que tuvieron que contestar los pueblos permiten hacer una "radiografía" -el término es muy empleado en la historiografía- de la sociedad española en ese tiempo halagüeño en que el reinado de Fernando VI se preparaba para disfrutar la paz conseguida en Aquisgrán el año anterior. No podían faltar en las "respuestas" los médicos, cirujanos (barberos y sangradores), boticarios, albéitares y ... maestros, sus nombres y sus salarios y la parte que correspondía pagar a los vecinos. Quizás peor pagado, pero el maestro estaba ya en el grupo de los distinguidos: aquellos que no se dedicaban a las labores agrarias ni al vil comercio; ya eran gente respetable y tratados de don. Muchos eran además hidalgos y se les exigía -a todoslimpieza de sangre y, desde luego, pulcritud en su vida y en su credo religioso. Así los hemos visto en las respuestas generales (véase anexo al final) y, a muchos de ellos, buscándolos por el nombre, en los memoriales que presentaron a la junta local del catastro, donde incluyeron todos sus bienes: tierras, bodegas, ganadería, censos -a favor y en contra-, así como los miembros de su familia, esposa e hijos, pero también criados -algunos los tenían-;

2. Citado en Gimeno Blay, F., "Aprender a escribir en el Antiguo Régimen", en Escolano Benito, A. (dir.), Historia ilustrada del libro escolar en España, Madrid, 1997, p. 302.

3. Todas las referencias pueden verse en https://catastrodeensenada.larioja.org/ gracias al Archivo Histórico Provincial de La Rioja (AHPLR) que ha desarrollado un gran trabajo digitalizando todo el Catastro. En PARES solo están digitalizadas las respuestas generales, pero en La Rioja, en esta fuente del AHPLR, están también las particulares y los memoriales. Agradecemos la constante ayuda de Micaela Pérez, directora del archivo, a lo largo de toda nuestra investigación.

4. Camarero Bullón, C. (dir.), El catastro de Ensenada, 1749-1756, Madrid, Ministerio de Hacienda, 2002. 
también declararon los salarios de sus otros trabajos. Además, hemos hecho una selección de documentos judiciales, en torno a unos 40, en los que hemos podido documentar una variada gama de casos en los que el maestro aparece ante el juez: maltrato a los niños -ya protestaban entonces los padres, es decir, que no es del todo cierto que se haya aceptado siempre el empleo del lema "la letra con sangre entra"-, maestros que no cumplían con su obligación, atrasos en el cobro del salario, quejas por el absentismo escolar, intrusismo profesional, etc.

Durante el tiempo dedicado a la investigación, profesores y estudiantes hemos comprobado que ni el maestro pasaba más hambre que sus vecinos, ni la situación en España era de las peores, como suelen pensar los que ven con ojos excesivamente negativos su historia, y menos aún en La Rioja, una región realmente privilegiada por la conjunción de rentas, agrícola -con el complemento de la viña- y ganadera e industrial ${ }^{5}$. En general, en España, la situación de escuelas y maestros no era muy diferente a la de los países de su entorno, al menos en el punto de partida, pues, de entrada, en la escuela del XVIII se enseñaba poco o nada -en realidad a leer y a escribir y cuatro normas recogidas en el catecismo-; pero como constata Carlo M. Cipolla, lo mismo ocurría en Francia, o incluso en Inglaterra, donde presuponemos con demasiado optimismo la influencia positiva en la alfabetización que tuvo la religión protestante. Cipolla recuerda que Engels escribió que la escuela dominical no enseñaba a escribir, pues consideraba esa ocupación demasiado terrenal para un domingo. ${ }^{6} \mathrm{Y}$ en todo caso, la Iglesia anglicana advertía a principios del siglo XIX al proponerse institucionalizar la educación que no iba a admitir a los niños pobres. En Torrecilla en Cameros, el maestro José Pérez de Tejada, que seguramente esgrimiría su procedencia del noble Solar de Tejada y, desde luego, exhibió su título de "maestro de primeras letras examinado y aprobado por la Congregación de San Casiano de la Villa de Madrid" ${ }^{7}$, resumía así sus obligaciones ante el ayuntamiento que le iba a contratar, en 1747:

a cargo y obligación según Dios me ha dado a entender, enseñándoles y adoctrinándoles a que sean humildes y temerosos de Dios, y a la obediencia que deben a los mayores como es bien notorio manteniéndoles en la escuela hasta las horas destinadas por Vuestra Majestad ${ }^{8}$.

5. Gómez Urdáñez, J. L., "La Rioja a comienzos de la Edad Moderna", Brocar 18 (1994), pp. 139-188.

6. Cipolla, C. M., Educación y desarrollo en Occidente, Barcelona, Ariel, 1983, pp. 33-34.

7. Sobre el relevante papel de la Hermandad de San Casiano en la profesionalización del magisterio en la Edad Moderna, véase Martínez Navarro, A., "Las primeras ordenanzas de la Hermandad de San Casiano de 1647", Revista de Ciencias de la Educación 111 (1982), p. 269 y ss.

8. AHPLR, Judicial, caja 1562/36. 
Es cierto que, tras la primera oleada industrializadora, España, junto con Italia y Portugal, se fue rezagando, pues hacia 1890, en España había 34.000 maestros, 20 maestros por cada diez mil habitantes, es decir, un maestro por cada 500 habitantes, una cifra que, como veremos luego en nuestro estudio, es muy superior a la ratio de La Rioja de mediados del XVIII, que se sitúa en un maestro por cada 900 o 950 habitantes (muy por encima de la media española de entonces). También veremos que La Rioja tiene maestros en más de la mitad de sus pueblos y tasas altas de alfabetización (quizás porque también tiene muchos clérigos en parroquias y conventos, que "enseñan de balde y quitan labradores", como recriminaba algún prominente ilustrado), así como salarios muy elevados, pero ciertamente, siglo y medio después las cifras son muy negativas e indican que se había avanzado muy poco, o quizás que se había retrocedido. Con todo, las diferencias no son tan escandalosas y aún España sale mejor parada que otros países, pues si en España había 20 maestros cada 10.000 habitantes, en Portugal había 8 y en Bélgica y en Italia 19. Prusia no destacaba precisamente con sus 72.000 maestros (y el doble de población que España), pues llegaba solo a 24, mientras Francia estaba por los $37 .^{9}$
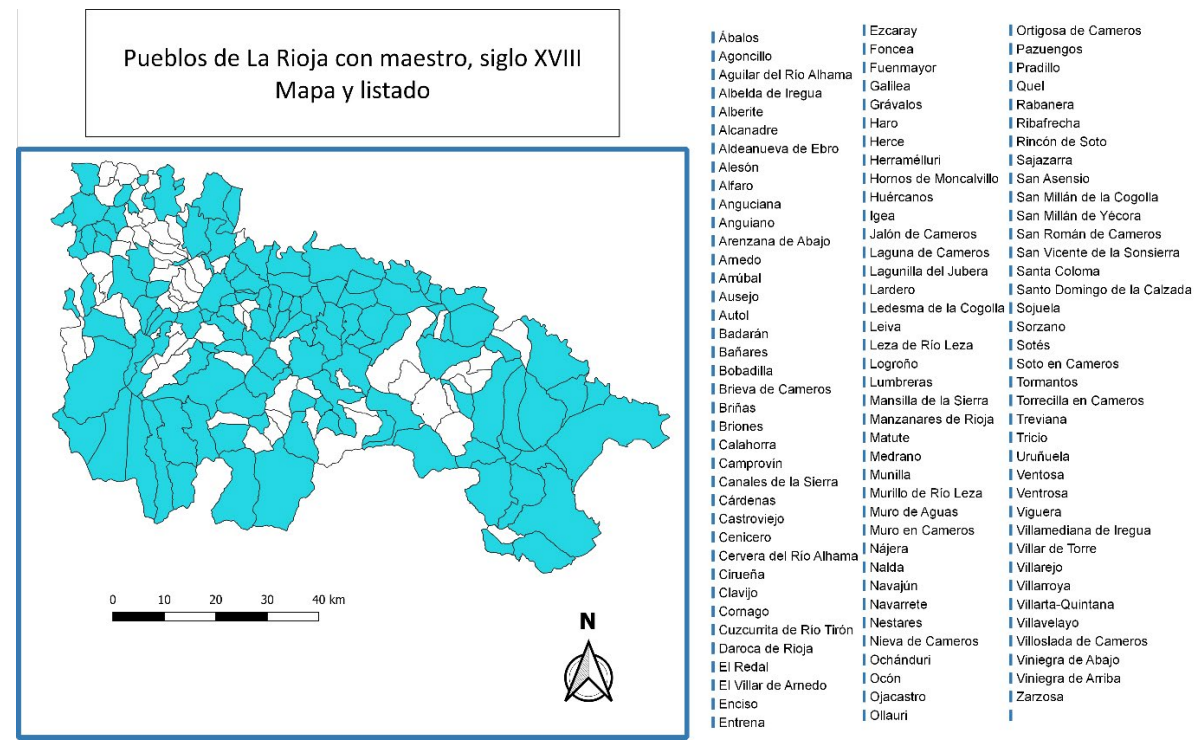

Figura 1. Pueblos de La Rioja con maestro, siglo XVIII. Mapa y listado.

9. Cipolla. C. M., Educación y..., p. 27. 
En el XVIII, las condiciones de maestros y escuelas son igual de variopintas en España que en el resto del occidente europeo. Las fuentes de financiación son las propias del Antiguo Régimen -municipio, particulares y caridad- y la estimación social también similar, aunque en La Rioja encontramos declaraciones de maestros que reflejan una alta estima por su labor. En La Rioja muchos son o se consideran del estado noble, algunos han sido examinados y todos deben exhibir la limpieza de sangre como condición primera. Un caso: Pedro de Uruñuela, elegido para maestro de Santurde en 1792, tiene limpieza de sangre y "examen en el arte y la pericia de escribir y contar" y dice saber "leer en letra antigua y moderna y formare muestras de diferentes letras y entendiere exemplares de cuentas de las 5 reglas". ${ }^{10}$ Otro ejemplo: Silvestre López de Angulo, maestro de Herramelluri en 1798, solicita el título de maestro de primeras letras a la Hermandad de San Casiano, para lo que demuestra, con testigos, su limpieza de sangre y su hidalguía:

... y que así dichos mis padres como abuelos y demás ascendientes, por una y otra línea fueron cristianos viejos limpios de toda mala raza de moros, judíos, recienconversos y de otra raíz infecta y reprobada, y notorios caballeros hijosdalgo de sangre y casa conocida en cuya fama quieta, y pacifica posesión estoy y estuvieron dichos mis padres sin cosa en contrario. ${ }^{11}$

Cipolla refleja que cuando el maestro tenía además una profesión complementaria era habitual declarar la otra, tanto en maestros como en maestras; estas preferían ser conocidas como costureras. En ocasiones, las maestras apenas sabían leer y escribir y solo enseñaban la doctrina cristiana, que se sabían de memoria. ${ }^{12}$ En Logroño veremos a las dos maestras declarar que enseñan a coser, pero una de ellas enseña a tañer el arpa. También hemos documentado dos casos en los que el maestro, que es también organista, declara solo esta profesión, pero en general, en España la profesión de maestro gozó siempre de notable prestigio social. Si con mucha frecuencia los maestros hacían también de organistas o entonadores es porque obviamente sabían Música, pero también porque ejercer un oficio cerca del clero local aumentaba su estimación.

10. AHPLR, judicial, 109/76.

11. AHPLR, judicial, $705 / 66$.

12. González Barrero, N., "Los maestros de primeras letras en la provincia de Madrid a través del catastro de Ensenada (1749-1756)", Historia y Memoria de la Educación 3 (2016), p. 207 y ss.; Ortega López, M., "La educación de la mujer en la ilustración española", en Simposium internacional sobre Educación e Ilustración, Madrid, 1981, pp. 193-223; Fernández Quintanilla, P., La mujer ilustrada en la España del siglo XVIII, Madrid, 1981. 


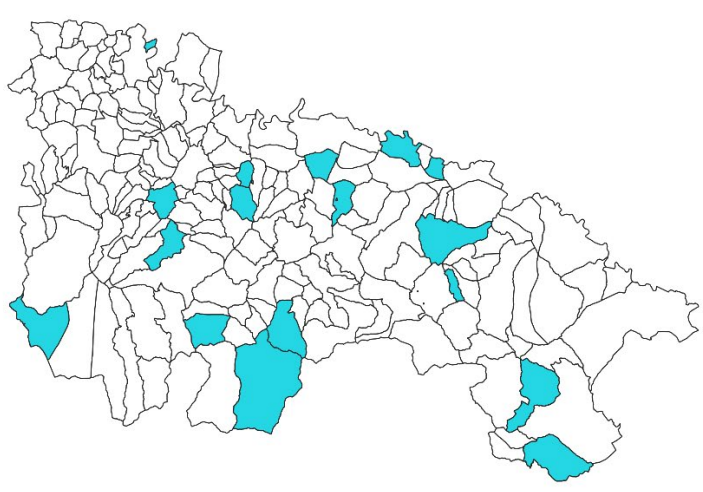

$\square$ Agoncillo
$\square$ Aguilar del Rio Alhama
$\square$ Badarán
$\square$ Briñas
$\square$ Canales de la Sierra
$\square$ Clavijo
$\square$ Igea
$\square$ Laguna de Cameros
$\square$ Lardero
$\square$ Lumbreras
$\square$ Matute
$\square$ Ocón
$\square$ Ortigosa de Cameros
$\square$ Santa Coloma
$\square$ Santa Eulalia Bajera
$\square$ Ventosa

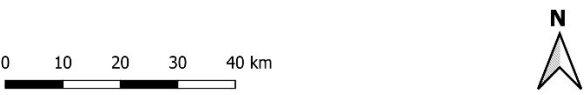

Figura 2. Pueblos donde el maestro es también organista.

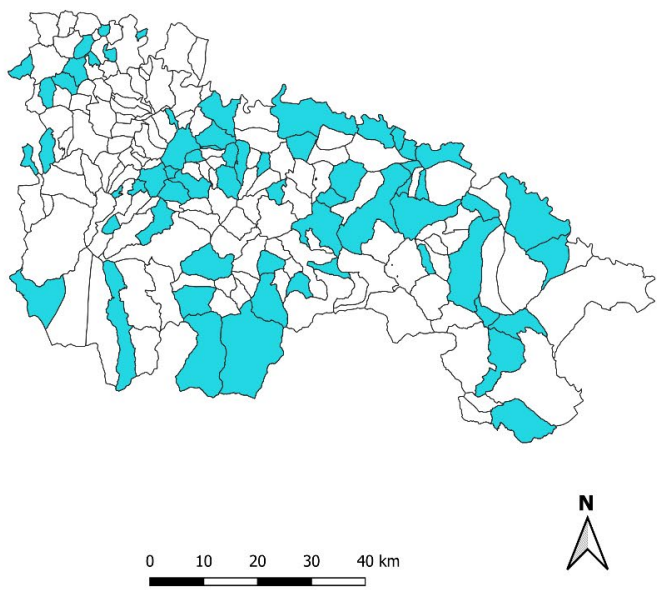

\begin{tabular}{|c|c|}
\hline Virivegra de Abajo & $\square$ Lciva \\
\hline$\square$ Villosladla de Cameros & $\square$ I ardeteo \\
\hline Villarta-Quintana & $\square$ Laguna de Cameros \\
\hline - Villarroya & $\square$ Igea \\
\hline Eventosa & $\square$ Huéreanos \\
\hline Tricis & $\square$ Hornillus ale Cameras \\
\hline - Soto en Camcras & $\square$ (óñalos \\
\hline - Sotés & $\square$ (alilca \\
\hline - Serzano & $\square$ Eil Villar de Arnedo \\
\hline W Santa Eulalia Bajera & $\square$ Fil Redal \\
\hline — Santa Engraçúa del Jubera & $\square$ Cuzcurtita de Río Tìrón \\
\hline W Santa Colonad & $\square$ Cenicero \\
\hline$\square$ San Billan de Yécora & $\square$ Cárdemas \\
\hline$\square$ sạjzarra & $\square$ Canciles ale la Sierrá \\
\hline D Ribafrecha & $\square$ Camprovin \\
\hline$\square$ Rabarocra & $\square$ Calahorra \\
\hline$\square$ Ortigosa de Cameros & $\square$ Briñas \\
\hline$\square$ Ocoin & $\square$ Bereeo \\
\hline - Ochánduri & $\square$ Bañes alle Río Tobía \\
\hline - Niewa de Cameros & $\square$ Badarản \\
\hline$\square$ Nájeria & $\square$ Arrubal \\
\hline - Muro en Cameros & $\square$ Arnedo \\
\hline W Micdrano & $\square$ Arguciana \\
\hline$\square$ Matute & $\square$ Aldcanuera de Fibro \\
\hline Lumbibreras & $\square$ Alcanactre \\
\hline$\square$ Logrofin & $\square$ Aguilar de1 Río Alhama \\
\hline$\square$ Leza cle Rio Leza & $\square$ Agroncillo \\
\hline
\end{tabular}

Figura 3. Pueblos donde el maestro tiene dos o más oficios. 
Las similitudes con los demás países europeos se producen también en el escaso tiempo de asistencia a clase, los días en que por las labores agrarias el maestro cerraba la escuela, los métodos rudimentarios de lectura y escritura, o las diferentes aportaciones de los padres de los niños -en dinero o en especie- según su nivel de instrucción, que en La Rioja solían ser también muy altas $^{13}$. En Jalón de Cameros los padres pagaban una fanega de trigo por el niño que aprendía a leer y escribir y media solo por leer (a 18 reales la fanega). Solo en algunos casos, lo que debían pagar los padres superaba al salario que daban los ayuntamientos, como ocurría en Cenicero, donde Pedro San Martín Mena cobraba 500 reales de los padres y 400 del concejo; o en Albelda, donde Isidro de Tejada cobraba 300 de la villa y 540 de los padres. También hay algunos pueblos en los que el maestro solo cobraba a los padres de los niños que iban a la escuela, como ocurría en Pradillo, donde José Sorzano obtenía unos 350 reales por ser maestro, pero 1.550 por su otra profesión, la de cirujano y sangrador. También había pueblos en los que el único pagador era una obra pía, como por ejemplo Alesón o Leza.

Aun así, estos casos excepcionales no pueden aminorar el interés por la instrucción de los niños que tenían los pueblos desde mucho tiempo atrás, lo que, como veremos en La Rioja, se nota por los elevados salarios que se pagan a los maestros y también por el interés que muestran los ayuntamientos cuando van a contratarlos. En algunos casos, incluso hay denuncias contra maestros que no cumplen, como ocurre con el de Cenicero, Pedro Blanco Ruiz, que tiene más afición a pescar y cazar que a enseñar en su escuela -por eso fue denunciado y Ilevado a juicio-, por lo que lleva tres años, 1748-50, sin recibir el salario, ni el del ayuntamiento ni el que le adeudan los padres, que deben estar hartos para llegar a hacer semejante declaración:

Del maestro y de la escuela, que los niños no sacan ningún provecho de ella, y de las enseñanzas de su maestro tampoco, por su ineptitud y poca habilidad para dicho ejercicio por ser sumamente corto de vista, cuanto por tener otros muchos defectos que le inhabilitan, y lo que más es, la poca asistencia y ningún cuidado que practica en el cumplimiento de su obligación. ${ }^{14}$

Por eso, el ayuntamiento decide hacer público en los pueblos de alrededor, pegando carteles, que busca un maestro "apto, hábil, y capaz para la enseñanza y educación de los niños". Aunque sea en fecha más tardía, 1842-43, en Huér-

13. Muy cerca de La Rioja, en Berlanga de Duero (Soria), hay un centro dedicado a la investigación sobre la cultura escolar, el CEINCE, con un precioso museo sobre la escuela y una espléndida colección de libros escolares -más de 50.000-, que dirige sabiamente Agustín Escolano Benito, a quien agradecemos su labor de gigante en medio de la adversidad.

14. AHPLR, Judicial, 1547/39. 
canos, también el pueblo se vuelca contra un mal maestro. Los padres dicen llevar a sus hijos a la escuela confiados "en el amor e interés paternal que debemos a nuestros hijos dedicados hoy a la instrucción primaria", lo que contrasta con el comportamiento del maestro, en el que notan "el total abandono de su ministerio, distraído en otras ocupaciones extrañas" y además su "crueldad rígida para con los niños y otros defectos sustanciales y escandalosos, repetidos y públicos en su conducta moral". Como no puede ser "la torpeza de todos los niños a la par" -dicen los padres-, el maestro ha de ser el responsable, como prueba que el visitador "a presencia del ayuntamiento, dio a entender que esta escuela es la que se halla en peor estado de toda la provincia". Los padres siguen denunciando la "atrocidad y barbarie en castigar a los niños, que llega al colmo con los hijos de Morgaño y de Pedro Aguado, de 5 y 6 años", que habían "quedado el del primero, a resultas de un gran palo que le sacudió en el pescuezo, inmóvil de él por mucho tiempo" y "el del segundo extraordinariamente estropeado y maltratado". ${ }^{15}$ Los casos de crueldad son frecuentísimos en todas las historias escolares de Europa, pero también hay casos como éste de denuncia y reparación, lo que prueba que el interés por la educación -y por el empleo de métodos menos sangrientos- no fue solo un asunto de las élites ilustradas que habían leído el Emilio de Rousseau ${ }^{16}$.

\section{La Rioja, región rica}

Sabemos por los trabajos de M. Lázaro, P. Gurría y F. Brumont que La Rioja era una región muy poblada ya en el siglo XVI ${ }^{17}$. Tras la crisis del XVII, que presenta su punto de inflexión entre la gran peste castellana de 1599 y la de 1631, la población se fue recuperando y el XVIII se anuncia como un siglo de crecimiento sostenido, como ha demostrado J.J. Alonso Castroviejo $^{18}$. Cuando se hace el catastro de las 22 provincias de Castilla, la actual comunidad pertenece a las dos provincias más extensas de Castilla, Burgos y

15. AHPLR, Judicial, 1446/3.

16. En muchas sociedades económicas de amigos del país -la materialización de las ideas utilitarias de Campomanes-, se atendió a la escuela, a la formación de maestros y en muchos casos, a la educación de las niñas y al apoyo de las maestras. Véase Arias de Saavedra Alías, I., "Las sociedades económicas de Amigos del País: proyecto y realidad en la España de la llustración", Obradoiro de Historia Moderna 21 (2012), pp. 219-245. Con todo, Campomanes pensó en una instrucción técnica, una preparación adecuada para los trabajadores que no interfiriera en el orden social de la separación de estamentos. Véase Escolano Benito, A., "Elogio y revisión de Carlos III", Historia de la Educación, revista interuniversitaria 7 (1988), pp. 7-18.

17. Lázaro Ruiz, M., Gurría García, P. y Brumont, F., "La population de la Rioja au XVle siècle", Annales de démographie historique 1, (1989), pp. 221-241.

18. Alonso Castroviejo, J. J., Problemática agraria, solución burguesa, Logroño, 17501833, Logroño, Instituto de Estudios Riojanos, 1991. 
Soria. Logroño era la ciudad más poblada de la provincia de Soria, con sus 6.600 habitantes, mientras Calahorra era la cabeza de un gran obispado que se extendía hasta el Cantábrico, incluyendo las Ilamadas Provincias Exentas, es decir, los señoríos vascongados. La Rioja Baja, que es la parte soriana, se configura como la región más poblada, con dos grandes núcleos, Calahorra y Alfaro, que pasan de los mil vecinos (algo más de los 4.000 habitantes), mientras a su alrededor se sitúan villas que se acercan a los 2.000 habitantes, o los sobrepasan como Cervera del río Alhama, la ciudad industrial que verá nacer la fábrica de lonas de Santa Bárbara y que comenzó en el XVIII su gran prosperidad. Al oeste del Iregua, se halla La Rioja Alta, que depende de Burgos, y tiene en Haro la principal ciudad, con unos 2.500 habitantes, rodeada de pueblos grandes y prósperos como Briones, con casi 2.000 habitantes. Nájera, con unos 1.800 habitantes, y Santo Domingo de la Calzada, con casi 2.000, son las cabeceras de comarcas bien diferenciadas, en cuyo entorno se sitúa una nube de pequeños pueblos, de entre 50 y 100 vecinos que caracterizan esta zona de minifundios y pueblitos próximos que mancomunan los servicios, a veces también el maestro y la escuela, a la que acuden niños de varios pueblos muy próximos, como ocurre en Alesanco, Torrecilla sobre Alesanco, Azofra y Cañas, por ejemplo.

Al sur, las sierras conforman una región muy diferente: son las sierras de la Demanda, Cameros, el monte Yerga y las estribaciones del Moncayo, tierras de pastos y ganados, en parte trashumantes, y de una actividad textil muy rentable. Los núcleos más importantes son Ezcaray, Torrecilla, Soto y Munilla, que pasan de los 2.000 habitantes. Son pueblos ricos, de gran pujanza industrial basada en la lana y el cáñamo, rodeados de aldeas de 400 a 800 habitantes como las Siete Villas en torno a Mansilla, Pedroso, Anguiano, Villoslada, etc. Menos poblada, la sierra sorprende por su riqueza y también por el interés mostrado tradicionalmente por mantener a toda costa la escuela, recurriendo al patronato para superar los problemas y, en ocasiones, dependiendo de las fundaciones creadas por los indianos, como es el caso de San Román y de Soto en Cameros ${ }^{19}$.

El total de habitantes que da el catastro para la actual Rioja, según los cálculos de Santiago Ibáñez (que aplica el coeficiente 4,21 para la conversión de vecinos en habitantes) es de 117.892, que se agrupan en 207 núcleos de población. ${ }^{20} \mathrm{El}$ número total de maestros en el catastro, que se eleva a 123 como hemos visto, nos da una media de un maestro por cada 958 habitantes. Como sabemos que hay algunos maestros más, la cifra disminuiría; también si eliminamos aldeas que apenas tenían población. En cuanto a su distribución, en La Rioja hay maes-

19. Zapater Cornejo, M., Escuelas de indianos en La Rioja, Logroño, 2007.

20. Ibáñez Rodríguez, S., Armas Lerena, N. y Gómez Urdáñez, J. L., Los señoríos en La Rioja en el siglo XVIII, Logroño, Universidad de La Rioja, 1996, pp. 27 y 28. 
tro en el 59,4\% de los pueblos, una cifra muy alta en comparación con la que conocemos de Cantabria (33\%), Guadalajara (36\%), Palencia (36 \%), y que se asemeja a los pueblos de la provincia de Madrid, donde en sus 99 pueblos había 53 que tenían maestro (53\%). ${ }^{21}$

Como ya presumíamos, La Rioja está bien situada, pero hemos de tener en cuenta las diferencias en el tipo de poblamiento -con Cantabria, especialmente- que distorsionan la realidad. De los estudios de Clotilde Gutiérrez se desprende que Cantabria tenía 521 pueblos, algunos muy próximos, y que muchos niños van al pueblo de al lado, lo que indica que un maestro es compartido por varios concejos, algo que sucede también aquí en la comarca de Nájera especialmente, y en pueblitos muy pequeños de las sierras, en las aldeas de Enciso o de la Villa de Ocón. ${ }^{22}$ Lo mismo ocurría con otros "conducidos" como médicos, boticarios y albéitares, que comparten varios pueblos.

Más clarificador puede ser constatar que pueblos tan pequeños como las aldeas del valle de Ocón, con unas decenas de vecinos tienen maestro y que lo mismo ocurre en pueblos de menos de 200 habitantes (50 vecinos), como Alesón (34 vecinos), San Millán de Yécora (41), Anguciana (49), Cirueña (42), Sojuela (44), Cellorigo (30), Villaverde de Rioja (35), Villarejo (22), Ledesma de la Cogolla (43), o Jalón de Cameros (45), donde a pesar de su escaso vecindario encontramos escuela y maestro. La baja población de estos pueblitos podría hacernos pensar en bajos salarios del maestro, pero no es el caso siempre. El maestro de Alesón, que pertenece al estado noble, percibe 600 reales y casa que le da la villa, aunque ha de hacer también de sacristán. Como en otros casos, su salario proviene de las rentas de una obra pía. En las mismas condiciones pero pagado por el ayuntamiento (y el complemento, por el cabildo parroquial) está el maestro de San Millán de Yécora (616 reales), o el de Villaverde (720), pero el de Cellorigo, un pueblo de tan solo 120 habitantes cobra 925 reales, mientras el de Ledesma cobra 880. El de Jalón de Cameros es un caso muy especial, pues el maestro ejerce de manera particular y cobra "una fanega por niño por leer y escribir y media solo por leer", como ya hemos visto. Valoramos la fanega en 18 reales, lo que no elevaría mucho su salario en un pueblo de tan solo 200 habitantes. No es el mismo caso que el del maestro de Navarrete, un poblachón cercano a Logroño, con casi 1.500 habitantes, donde el maestro cobra 600 reales del ayuntamiento y 45 fanegas de trigo que le pagan los padres, una por el niño que "lee y cuenta" y media por el que "solo lee", lo que da un total de 810 reales, más que lo que le paga el concejo. Hay muchos casos así como puede comprobarse en la tabla al final.

21. Gutiérrez, C., Enseñanza de primeras letras y latinidad en Cantabria, 1700-1860, Universidad de Cantabria, 2001. Para Madrid, González Barrero, N., Los maestros de primeras letras en la provincia de Madrid a través del catastro de Ensenada (1749-1756), Historia y Memoria de la Educación 3 (2016), p. 207 y ss.

22. Gutiérrez, C., Enseñanza de primeras..., pp. 117-119. 
En el otro extremo se sitúan los maestros de los pueblos grandes, los de Haro, por ejemplo, que a fines del XVIII tenían ya una escuela en la que enseñaban varios, aunque en el catastro solo figura uno, que gana 800 reales y habita en la casa que le da el ayuntamiento, junto a un maestro de Gramática, que gana 2.000 reales. Como además Haro tiene convento de agustinos, algunos niños reciben enseñanza de ellos. Probablemente Haro era la ciudad mejor escolarizada de La Rioja, pero no todos sus maestros figuran en el catastro, quizás porque el concejo solo pagaba uno. Los de su comarca gozaban de la misma buena situación: el de Briones, que se preciaba de descender de nobles, recibía un salario de 1.650 reales, pero además tenía viñas y dos bodegas con cubas de no menos de 2.000 cántaras. Es el típico maestro rico riojano de la zona vinatera cercana al Ebro, parecido al de Anguciana, que vive en la casa del ayuntamiento "en la que se celebran las juntas" y en ella tiene la escuela. Con un salario de 1.376 reales y haciendo de notario y sacristán, está entre los mejor pagados; como el de Cenicero, que con poco más de 1.000 reales de salario, tiene 10 viñas, mucha tierra blanca y bodega. Un caso muy especial en la comarca jarrera es el de Ollauri, que cobra su salario en vino, 70 cántaras, y se obliga como sacristán a poner el vino en las misas, para lo que recibe otras 20 cántaras más.

En La Rioja Baja, hay igualmente maestros ricos, pues en general los pueblos son grandes. El maestro de Igea, que tiene 2.000 habitantes, haciendo también de organista, Ilega a cobrar casi 2.000 reales; el de Aldeanueva, que también es notario apostólico, obtiene 1.158 y solo 15 por su otra profesión, en realidad un cargo ligado a la vida de la parroquia mal pagado, pero de gran estima social. No está muy bien situado el de Calahorra, que seguramente tenía mucha competencia con los clérigos de la catedral y los frailes y monjas de sus muchos conventos; el ayuntamiento le daba 510 reales, pero los vecinos que le enviaban niños le pagaban 30 fanegas de trigo, unos 500 reales más.

También en la media salarial aparece La Rioja en buena posición. En Cantabria, el pueblo que más salario paga solo llega a los 460 reales, una cifra ampliamente superada en los pueblos riojanos, incluso en los pequeños, como hemos visto; también los padres pagan menos y son menores las rentas de las obras pías destinadas a costear el maestro ${ }^{23}$. En la provincia de Madrid, los salarios son también más elevados, alcanzando una media de 600-700 reales, con algunos de maestros realmente privilegiados que llega a ganar entre 2.000 y $3.000 .^{24}$

En definitiva, La Rioja presenta una cifra elevada de maestros y relativamente están bien remunerados. Como pertenecen de lleno a la sociedad agraria, muchos complementan sus rentas con las huertas de subsistencia y viñas y con una

23. Gutiérrez, C., Enseñanza de primeras..., p. 149.

24. González Barrero, N., Los maestros..., p. 207 y ss. 
propiedad que a veces llega a ser importante, y la mayoría desempeñan otros oficios. Hemos contado organistas, notarios, escribanos, fieles de fechos, sacristanes, campaneros y hasta cirujanos. Así pues, los maestros del XVIII son todavía, como los definió Antonio Domínguez Ortiz, "una figura desdibujada". ${ }^{25}$ Atienden a mil cosas además de las particulares y no es extraño que el maestro cierre la escuela en los tiempos más activos del ciclo agrario, obviamente también durante el verano, pero igualmente en los días de vendimia y de recogida de la oliva; es también normal que falte a menudo, lo que a veces autorizan los propios contratos con los ayuntamientos que citaban como motivo el de sus necesidades personales o el de su otra profesión ${ }^{26}$. Tampoco el horario era muy amplio, pero el maestro estaba al cuidado de los niños en todos los actos públicos, especialmente durante las celebraciones religiosas, desde los entierros y procesiones a las novenas, las vísperas o las misiones. El tiempo de escuela era escaso y los niños solo acudían entre los seis y los doce años, que es el periodo que todavía fijó como obligatorio la ley Moyano en $1857 .^{27}$

\section{Maestros y escuelas en La Rioja}

Varios siglos antes de que la Constitución de 1812 proclamara que "en todos los pueblos de España se establecerán escuelas de primeras letras" (artículo 366) y obligara a los ayuntamientos a "cuidar de todas las escuelas" (artículo 321), muchos pueblos habían logrado mantener y costear con fondos del concejo un maestro de primeras letras. La alta tasa de alfabetización que hallaron Marie Hélene Buisine y Jacques Soubeyroux en la ciudad de Logroño en el siglo XVIII ${ }^{28}$ se debe, sin duda, a la existencia de al menos cuatro maestros de primeras letras en la ciudad, sin olvidar, claro está, los muchos conventos de la ciudad, especialmente el de jesuitas, donde se proporcionaba enseñanza de primeras letras y también de Gramática y Latín, necesarios para acudir a la universidad ${ }^{29}$. En realidad, como en tantas ciudades con colegio de la Compañía, este era el verdadero centro de enseñanza "público" de la ciudad, con sus cuatro maestros, "dos maestros de primeras letras de leer y escribir" y "dos maestros de gramática". El ayuntamiento se refiere a él siempre como "el Colegio" y lo costea

25. Domínguez Ortiz, A., La sociedad española en el siglo XVIII, Barcelona, Ariel, 1986, p. 173.

26. Laspalas Pérez, F. J., "La condición social y profesional de los maestros de primeras letras en Navarra durante la segunda mitad del siglo XVIII", Príncipe de Viana 254 (2011), p. 492.

27. Escolano Benito, A. (dir.), Historia ilustrada del libro escolar en España, Madrid, 1997.

28. Buisine, M. H. y Soubeyroux, J., "La realidad social: el dominio de analfabetismo", Historia de la ciudad de Logroño, Logroño, 1995, vol. IV, p. 127 y ss.

29. Rodríguez San Pedro Bezares, L. E., "De las escuelas de Logroño a las universidades", Historia de la ciudad de Logroño, Logroño, 1995, vol. III, pp. 357-376. 
directamente, dándole al año 3.000 reales "por alimentos", que carga sobre el impuesto de las sisas. ${ }^{30}$

No son muchos ocho maestros para una población de unos 6.600 habitantes, pero aun así la tasa de analfabetos -similar a la de Madrid- era más baja que en algunas ciudades de las que tenemos datos, aunque no ocurría igual en el caso de las mujeres. Como era de esperar, la explicación está en que los pueblos tuvieron conciencia de la necesidad de que los hombres aprendieran a leer y escribir, pero no las mujeres, pues apenas encontramos referencias a escuelas de niñas y menos aún, a escuelas de niñas en las que se pague con fondos del común a las maestras. Ni la Constitución, ni el célebre informe de Manuel José Quintana se ocuparon de la enseñanza de las mujeres, salvo para elogiar su dedicación a las "labores propias de su sexo" -que es lo que predominará luego en la enseñanza, además de la escritura y la lectura y la Religión-, es decir, lo necesario para hacer de ellas buenas madres y esposas. ${ }^{31}$

Con todo, en Logroño, el catastro cita dos maestras, una es María Pérez de Mauleón, de 56 años, que vive en la calle Ollerías, y se emplea en hacer medias e hilar, pero también en "enseñar a unas 20 niñas a hacer media y leer", lo que no le permitía vivir si no fuera por la caridad de los vecinos. Mejor posición parece ocupar Joaquina de Cárdenas, de 38 años, la otra maestra, que "enseña a las niñas a coser y a tañer el arpa", por lo que cobra entre 330 y 440 reales (menos que los jornaleros). También hay un hombre, Juan José Llorente, un joven organista y maestro de capilla de La Redonda, de 23 años, que da clases (probablemente de Música) a señoritas, por lo que gana 780 reales. ${ }^{32}$

Con todo, hay que recordar que la situación precaria de la educación de niñas es paralela a la condición general de la mujer. Los peritos del catastro no consideraron a la mujer como "sujeto fiscal", prácticamente en ningún caso. En Logroño, la partera -que por cierto ganaba más del doble que el maestro mejor pagado- no figuraba como perceptora de salario, pues era su marido el que lo cobraba. La declaración de su situación es la siguiente: "Joseph Martín, por la utilidad que le deja el oficio de partera que ejerce Anto-

30. Abad León, F., Radiografía histórica de Logroño, Logroño, 1978, p. 209.

31. En efecto, la enseñanza de las niñas quedó en un nivel secundario, aunque en nuestro estudio descubrimos algunos casos en que las niñas asistían a la escuela. Pero hasta la ley Moyano, que impone la erección de una Normal femenina en toda capital de provincia -una proeza para el momento en que se decretó-, la enseñanza solo se contemplaba para los niños y además, no había maestras, salvo excepcionalmente y casi siempre de manera privada, que es como todavía Quintana pretende que se les eduque. Si solo se trataba de conseguir un matrimonio ventajoso, no tenía sentido que lo pagara el Estado. Natividad Araque repara en la iniciativa de Quintana sobre los conventos y la enseñanza a las niñas, solo hasta los 10 años. Véase Araque Hontangas, N., Quintana y la instrucción pública, Madrid, Universidad Carlos III, 2013, p. 51. También de gran interés el número 26 (2007) de la revista Historia de la educación, Revista interuniversitaria, coordinado por Consuelo Flecha.

32. Citado en Buisine, M. H. y Soubeyroux, J., "La realidad social...", p. 139. 
nia de Vicuña, su mujer, 2.200 reales" $^{\prime 33}$. Hay algunas mujeres que salen del anonimato en el catastro, pero suelen ser o viudas de un maestro de algún gremio, o tenderas. Citaremos el caso muy especial de Cathalina de Leyva, dueña de la soguería en que trabajan para ella tres aprendices, un oficial y un hijo y otro soguero.

En los pueblos, la situación de la mujer es si cabe peor, pues no existen esas maestras, excepcionales y más propias de la ciudad. Pero quizás la ratio de maestro y alumnos mejora en el mundo rural, mientras el esfuerzo para los pequeños pueblos aumenta considerablemente al tener que buscar fondos para pagar el salario y casa para el maestro teniendo rentas escasas. Casi siempre el salario era en especie, trigo y cebada; a veces se completaba con vino -en el valle- o con corderos -en la sierra- y, desde luego, estaba generalizado que contribuyeran los niños con alguna aportación. Salario, casa facilitada por el ayuntamiento y aportación de las familias eran los tres conceptos que componían la paga del maestro y así pasaron a la ley Moyano, manteniéndose muchos años, prácticamente hasta los cambios introducidos en la legislación educativa por Villar Palasí en $1970^{34}$.

Y es que en el fondo, el maestro siempre formó parte de la sociedad campesina, se fundió en ella y sufrió, para lo bueno y para lo malo, el discurrir de la vida agraria. Él mismo fue a veces propietario de tierras y viñas, o de algún hato de ganado. No se le pedía que fuera un intelectual -de hecho, apenas encontramos libros en los inventarios post mortem de los maestros del XVIII-, solo que enseñara a leer y a escribir y, desde luego, la Religión Católica, única y obligatoria (hasta la Constitución de 1869). Leer y escribir -y como mucho contar- era en la práctica el único objetivo de la escuela, es decir, vencer el analfabetismo, cuyo dominio era enorme, como sabemos.

La Rioja del XVIII presenta, sin embargo, una situación bastante favorable en lo relativo a la alfabetización y a la distribución de maestros y escuelas, lo que contrasta con la situación posterior a la guerra de la Independencia, que representó claramente un paso atrás. Un informe de los jefes políticos de las provincias remitido en 1821 a las cortes señala las grandes carencias que se

33. En todos los pueblos ocurre así, en cualquier oficio, incluso el de bordadora o el de sardinera, como hemos constatado en Haro, por citar un ejemplo.

34. El proyecto de construir escuelas y al lado casas para los maestros fue una obsesión en los ayuntamientos riojanos ya antes de la Segunda República, como hemos demostrado en todos los estudios regionales publicados (Cenicero, Pradejón, Quel, Autol, Aldeanueva). El plan Bergamín de 1914 supuso un notable impulso a la profesionalización del maestro, pero no abordó el problema de la falta de escuelas. La República, por decreto de 29 de septiembre de 1931, lo intentó, pero tropezó con la falta de fondos. Todas las escuelas de los pueblos que hemos estudiado en La Rioja, los ya citados, fueron comenzadas antes o durante la Segunda República, pero no se terminaron hasta la década de 1950. Hasta entonces los ayuntamientos alquilaban bajos de casas, o habilitaban como escuela algún almacén. 
encontró el Estado liberal en su nacimiento: no había escuelas ni maestros en cientos de pueblos. En lo concerniente a la provincia de Burgos (a la que pertenecía toda La Rioja occidental), había 279 sin maestro; en la de Soria (que incluye La Rioja oriental) faltaban 91 escuelas $^{35}$. La guerra catastrófica arruinó las haciendas municipales, muchos pueblos fueron incendiados y saqueados, mientras las primeras desamortizaciones -la de Godoy y la josefina- mermaron el patrimonio de propios y comunes, de donde salía el grueso del salario del maestro. La revolución liberal no podía empezar desde más abajo en su pretensión de transformar súbditos en ciudadanos ${ }^{36}$.

Pero en el XVIII, prácticamente todos los pueblos riojanos que superaban los 50 o 60 vecinos tenían escuela y maestro "conducido" por el concejo; nos sorprenderá ver pueblos que no llegaban a 150 habitantes y tenían maestro y, además, bien pagado. Veremos después las condiciones en que desarrollaban su trabajo, pero antes conviene precisar que los 123 maestros que dan Buisine y Soubeyroux para toda La Rioja según el catastro de Ensenada viven en una región muy próspera, tanto el valle de la viña, el cereal y la huerta, como la sierra del ganado estante y trashumante y de la actividad textil y comercial.

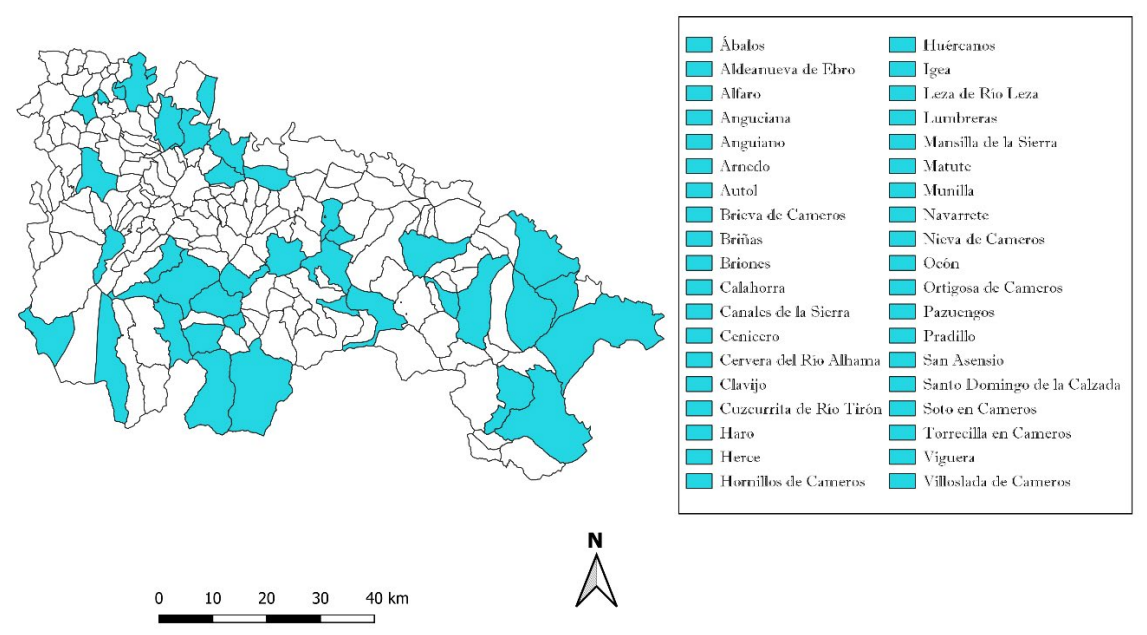

Figura 4. Pueblos donde el maestro cobra más de 1000 reales.

35. Araque Hontangas, N., Quintana y..., p. 77 y ss.

36. Buisine-Soubeyroux, M. H., Alfabetización, educación y sociedad en tiempos de Espartero (1831-1875), Logroño, Universidad de La Rioja, 1999. 


\section{Conclusiones}

El interés por la escuela fue en aumento durante el siglo de la Ilustración, pues en España este movimiento filosófico -que en España tuvo una expresión más práctica y menos especulativa- contó con numerosos agentes activos en favor del progreso que creían más en los resultados que en los debates intelectuales ${ }^{37}$. Campomanes dio la nota al plantear la educación de los obreros manuales y al preconizar una "educación popular", mientras los diputados de Cádiz Ilevaban la obligatoriedad de la escuela a todos los pueblos de España. Antes, el catastro de Ensenada reflejó que el maestro era ya una figura pública a mediados del XVIII y sobre él recaería en el futuro el progreso social que todos atribuían a la educación ante la nueva era que cambiaba súbditos por ciudadanos. Desde mucho tiempo atrás, las ideas de bien público y general, aplicadas a la educación, descansan en una tradición que se remonta a los humanistas del siglo XVI, a la secularización de los saberes y a la necesidad de leer, que llegó hasta los pueblos españoles, donde la figura del maestro pagado por los concejos, de bienes de propios o con las rentas de alguna obra pía -todavía la caridad-, fue adquiriendo el carácter de servidor público, como los médicos, boticarios, albéitares, notarios y escribanos. En definitiva, el XVIII generalizó la figura del maestro y ya no se puso en duda que la escolarización solo podía ser obligatoria, por mucho que aun décadas después -incluso en el siglo XX- los maestros denunciaran el absentismo escolar, la incuria de los padres, el eterno problema que la escuela española ha soportado hasta hace bien poco. ${ }^{38}$

La Rioja, próspera y bien poblada desde el siglo XVI a causa de la confluencia de un valle agrícola rico y unas sierras ganaderas enormemente dinámicas, presenta unos buenos niveles de escolarización relativamente. Los pueblos, incluso algunos muy pequeños, mantienen su maestro. Las ciudades grandes tienen varios y en la mayoría, en las que hay conventos, hay también enseñanza, a veces la que se dirige a las élites. Peor situación tienen las niñas, pues como en toda Europa, solo se les considera sujetos de una educación muy especial, que conduce al matrimonio y a la maternidad. Las sociedades económicas, que en otras regiones dedicaron un lugar a la necesidad de instruirlas, no brillaron aquí en esa labor, y la Riojano-castellana dirigida por el conde de Hervías -que enviaba a sus hijas a educarse a Burdeos- no dedicó al asunto ni un minuto. Con todo y eso, los maestros de la región están dignificados, ganan sueldos por encima de los jornaleros y algunos, se equiparan a otras profesiones de "la pluma", mientras la mayoría hacen también de organista o campanero, fiel de fechos o escribano, y muchos tienen hacienda, bodega y viñas, o ganado, en

37. Gómez Urdáñez, J. L., Fernando VI y la España discreta, Madrid, Punto de Vista editores, 2019, p. 335 y ss.

38. Véase un caso en Buisine, M. H., "El interés por la educación", en Gómez Urdáñez, J. L. (dir.), Aldeanueva histórica, Logroño, 2015, p. 231y ss. 
algunos casos tan buena posición como para ser considerados ricos. Este fue el nivel de partida de todos los esfuerzos que se iban a hacer durante el siglo XIX por superar los obstáculos, los que los ilustrados venían denunciando desde que vieron que la educación era la clave de la transformación de un país.

Al final aportamos en una tabla los datos más relevantes obtenidos en la investigación de las dos series documentales del Archivo Provincial de La Rioja que hemos citado al principio: el catastro del marqués de la Ensenada, respuestas generales $y$, en algunos casos, respuestas particulares y memoriales, y la sección Judicial, en la que hemos seleccionado no menos de 40 expedientes. Obviamente, la investigación puede continuar con las mismas fuentes y, desde luego, con los protocolos en el mismo archivo, pues hemos trabajado solo una pequeña parte de un inmenso fondo documental.

\section{Bibliografía}

Alonso Castroviejo, J. J., Problemática agraria, solución burguesa, Logroño, 1750-1833, Logroño, Instituto de Estudios Riojanos, 1991.

Araque Hontangas, N., Quintana y la instrucción pública, Madrid, Universidad Carlos III, 2013.

Arias de Saavedra Alías, I., "Las sociedades económicas de Amigos del País: proyecto y realidad en la España de la Ilustración", Obradoiro de Historia Moderna 21 (2012), pp. 219-245.

Buisine-Soubeyroux, M. H. y Soubeyroux, J., "La realidad social: el dominio de analfabetismo", en Gómez Urdáñez, J. L. (coord.), Historia de la ciudad de Logroño, Logroño, 1995, vol. IV, p. 127 y ss.

Buisine-Soubeyroux, M. H., Alfabetización, educación y sociedad en tiempos de Espartero (1831-1875), Logroño, Universidad de La Rioja, 1999.

Buisine-Soubeyroux, M. H., "El interés por la educación”, en Gómez Urdáñez, J. L. (dir.), Aldeanueva histórica, Logroño, 2015, p. 231 y ss.

Camarero Bullón, C. (dir.), El catastro de Ensenada, 1749-1756, Madrid, Ministerio de Hacienda, 2002.

Cipolla, C. M., Educación y desarrollo en Occidente, Barcelona, Ariel, 1983.

Domínguez Ortiz, A., La sociedad española en el siglo XVIII, Barcelona, Ariel, 1986.

Escolano Benito, A. (dir.), Historia ilustrada del libro escolar en España, Madrid, 1997.

Escolano Benito, A., "Elogio y revisión de Carlos III", Historia de la Educación, revista interuniversitaria 7 (1988), pp. 7-18.

Fernández Quintanilla, P., La mujer ilustrada en la España del siglo XVIII, Madrid, 1981. 
Gimeno Blay, F., "Aprender a escribir en el Antiguo Régimen", en Escolano Benito, A. (dir.), Historia ilustrada del libro escolar en España, Madrid, 1997.

Gómez Urdáñez, J. L., "La Rioja a comienzos de la Edad Moderna", Brocar 18 (1994), pp. 139-188.

Gómez Urdáñez, J. L., Fernando VI y la España discreta, Madrid, Punto de Vista editores, 2019.

González Barrero, N., "Los maestros de primeras letras en la provincia de Madrid a través del catastro de Ensenada (1749-1756)", Historia y Memoria de la Educación 3 (2016).

Gutiérrez, C., Enseñanza de primeras letras y latinidad en Cantabria, 17001860, Universidad de Cantabria, 2001.

Ibáñez Rodríguez, S., Armas Lerena, N. y Gómez Urdáñez, J. L., Los señoríos en La Rioja en el siglo XVIII, Logroño, Universidad de La Rioja, 1996.

Laspalas Pérez, F. J., "La condición social y profesional de los maestros de primeras letras en Navarra durante la segunda mitad del siglo XVIII", Príncipe de Viana 254 (2011).

Lázaro Ruiz, M., Gurría García, P. y Brumont, F., "La population de la Rioja au XVle siècle", Annales de démographie historique 1 (1989), pp. 221-241.

Martínez Navarro, A., "Las primeras ordenanzas de la Hermandad de San Casiano de 1647", Revista de Ciencias de la Educación 111 (1982).

Ortega López, M., "La educación de la mujer en la ilustración española", en Simposium internacional sobre Educación e llustración, Madrid, 1981, pp. 193-223.

Rodríguez San Pedro Bezares, L. E., "De las escuelas de Logroño a las universidades", en Gómez Urdáñez, J. L. (coord.), Historia de la ciudad de Logroño, Logroño, 1995, vol. III, pp. 357-376.

Zapater Cornejo, M., Escuelas de indianos en La Rioja, Logroño, 2007. 


\section{Anexo. Maestros en los pueblos de La Rioja, según el catastro de Ensenada (con algunas notas de la sección judicial del AHPLR) ${ }^{39}$}

Ábalos, 45 vecinos. Domingo Francisco de Bolíbar y Dueta. Pertenece al Estado Noble, tiene 63 años, está casado y tiene una hija soltera mayor de edad. No especifica qué parte le pagan los niños y qué parte la villa, pero su renta total percibida asciende a 1000 reales según los autos y respuestas generales. En su memorial afirma que gana 70 ducados de vellón (770 reales). Vive en la casa parroquial.

Agoncillo, 76. Lorenzo de Rivas, organista (704 reales) y maestro de primeras letras (386 reales).

Aguilar del Río Alhama, 349. Hay un maestro de niños, con salario de 550 reales. Además, por regir el reloj percibe 66 reales y por el ejercicio de organista 261. En total, gana 867 reales.

Alesanco, 147. No consta maestro.

Alesón, 34. Pedro López de Tejada, de 52 años, tiene 4 hijos, todos menores de edad. Como maestro cobra 300 reales de una obra pía. También es sacristán. Es noble y tiene hacienda propia. La villa le da la casa donde vive, en la misma escuela. Tiene alguna tierra, poca: una pieza de cereal, dos viñas y un Ileco. Dice: "así bien recibo por el oficio de Maestro de primeras letras trescientos reales de vellón, los cuales me los paga cada año Manuel de Sierra vecino de esta villa de los caudales que dejó y mandó imponer para dicho maestro Martín de Belasco, vecino de esta villa".

Albelda de Iregua, 157. Isidro Fernández de Tejada, cobra 300 reales de vellón de la villa y 540 de los niños.

Alberite, 126. Matías de Cabezón.

Alcanadre, 173. Diego Fernández, del estado general, casado y sin hijos, cobra 540 reales como maestro y 374 por ser fiel de fechos y encargarse del reloj, tiene casa propia, 4 piezas de sembradura de secano de una fanega y de $3^{\text {a }}$ calidad, una pieza de media fanega, una pieza de fanega y media con carga perpetua de aniversario por lo que paga 6 reales anuales, pieza de cuatro celemines con olivos de segunda calidad, una viña de media fanega con cargas de 40 ducados a favor de las pías ceremonias de las benditas animas, 2 viñas de nueve celemines, otra viña de media fanega con 2 olivos, viña de 3 celemines, viña de una fanega y cuatro celemines, olivar de secano de medio celemín, tres piezas incultas, un corral y media bodega, una mula y cuatro cabras y un jumento.

39. Hay algunos pueblos en los que el maestro no aparece en el catastro. La cifra junto al nombre del pueblo pueblo índica el número de vecinos. 
Aldeanueva de Ebro, 416. Gerónimo Baquedano, del estado general, casado y con una sobrina viviendo en su casa, cobra 1.158 reales como maestro y 15 como notario apostólico.

Ignacio Briñas, del estado general, casado y con una criada a su servicio, cobra 1.745 reales como maestro de gramática.

Alfaro, 1.030. Ambrosio Moreno, maestro de primeras letras, 900 reales de utilidad y 274 de salario, tiene casa, pero hipotecada con un censo, no tiene nada, vive de su trabajo.

Lázaro de Meca, maestro de primeras letras, 600 reales de utilidad y 274 reales de salario.

Juan Ximénez del Portillo, maestro de Gramática, 660 reales de utilidad y 5 reales de salario, tiene tierra, varias casas, pero muchos censos en contra y gana poco.

Almarza de Cameros, 69. No consta maestro.

Anguciana, 50. Francisco Pérez, maestro de primeras letras de 36 años. Está casado y tiene al cargo a un sobrino menor. Salario maestro: 32 fanegas de trigo por maestro y sacristán. De ellas, 4 son de la villa y el concejo, 14 del vecindario y 14 del cabildo. Le dan ocho cántaras de mosto y "además, dos ducados por cada tina que Ilena de uva en el diezmo". Es también Notario y sacristán. Entre los tres trabajos gana 800 reales. Su renta total asciende a 800 reales más 32 fanegas, que equivalen a 576 reales, lo que nos da en total 1.376 reales.

Anguiano, 376. Juan Francisco González. Salario maestro: 1100 reales.

Arcefoncea, 22. No consta.

Arnedillo, 236. No consta.

Arnedo, 633. José García Moreno, 800 reales igual a 8 fanegas (por 20 alumnos). Es además notario.

Arenzana de Abajo, 98. José Manzanares y Larrea. Casado, 43 años, cuatro hijos. 28 fanegas de trigo (equivalen a 420 reales). Paga 75 reales anualmente a su vecino Antonio de Salas en concepto de vivienda. Además es lechero.

Arenzana de Arriba, 38. No consta.

Arrúbal, 35. Manuel Alfaro. Maestro de primeras letras, 25,5 reales. Es además tocador de campanas (51 reales), fiel de fechos (51 reales) y cirujano-barbero (510 reales). Casado. Su única familia es un hijo de menor edad.

Ausejo, 398. José Andrés Izquierdo. Casado. 660 reales. No tiene ya familia.

Autol, 443. Lorenzo Fernández de Bobadilla, 830 reales de salario. Su familia es un hijo de menor edad y una hija.

Bernardo Isava de Mirafuentes, maestro de Gramática, 1420 reales. Su familia es un hijo de menor edad, una cuñada y una criada. 
Azofra, 48. No consta

Bañares, 110. Maestro de primeras letras, 10 fanegas de trigo la villa por la enseñanza a los pobres huérfanos de ella. Equivalen a 180 reales.

Baños de Rioja, 36. No consta.

Baños de río Tobía, 76. No consta.

Bobadilla, 31. No consta.

Brieva de Cameros, 108. Miguel García Moreno, del estado general, gana 870 reales de vellón. Es soltero y tiene con él a una hermana y un sobrino de menor edad. "También se utiliza del ganado de lana fino que se considera vende en cada un año de 12 reales de vellón". Tiene pastando 4 ovejas y 15 carneros en la provincia y en los términos de la villa un cerdo y una prímala de cabrío. El esquilmo del ganado de lana fino anterior importa, según regulación hecha, 208 reales y medio.

Briñas, 73. Manuel Pérez Gómez, de 38 años. 400 por maestro niños, 400 por organista y 60 por el pesaje laberío. Tiene un hijo de 13 años estudiando Gramática y dos hijas, una de 16, sirviendo en Haro y otra de 9. También percibe 50 reales por enseñar doctrina cristiana. Paga 60 reales anuales por la casa propia del cabildo de beneficiados de la iglesia. Percibe 60 reales de la notaría del cabildo.

Briones, 434. Maestro Juan Antonio Martínez de Zorrilla, del estado general pero descendiente de nobles. Casado con tres hijos menores y dos hijas. Tiene como salario 150 ducados de la villa como de los niños (1650 reales). Poseía una finca de 84 pies de largo por 15 de ancho y 30 de alto, en ella hay una bodega que contiene: 1 tina de cabida de 80 arrobas, más dos cubas de 150 cántaras, más una caballería, más el arriendo de una parte de ella a Manuel A. por 180 reales al año. Otra bodega de 30 pies de calado mas 3 cubas de cabida de 500 cántaras por la recolección de sus frutos. Varias viñas. Otra finca a medias con Manuel Angondo. Tiene un censo de 400 ducados a favor del convento de la mayor de Santa Clara, otro de 400 ducados y doce reales a favor de la capellanía de Ceballos y 286 ducados a favor de la cofradía de la Santa Vera Cruz.

Cabezón de Cameros, 51. No consta.

Calahorra, 1.046. Maestro Gabriel Velázquez, del estado general. Casado, con 4 hijos menores, dos niños de 10 y 8 años. Una sobrina. Sin más familia. Es también Labrador por lo que percibe 286 reales. Tenía como salario de maestro 30 fanegas de trigo (480 reales) que le pagan los vecinos que envían niños a la escuela además de 510 reales.

Camprovín, 75. Maestro Juan Manuel Martínez. Maestro, sacristán y organista. Tenía como salario de maestro y organista 38 fanegas de trigo que el concejo le pagaba anualmente además percibía de la fábrica 12 fanegas de trigo; en 
total 750 reales anuales. Como sacristán percibía 12 fanegas de trigo y de ganadero ganaba 34 reales. Poseía dos cabezas de ganado y tres cerdas crías.

Canales de la Sierra, 232. Maestro José de Baños, del estado noble. Casado, tiene un hijo estudiando, otro menor más tres hijas. Además es organista y percibe por los dos oficios 1600 reales.

Cárdenas, 69. Hay un maestro de niños del que no se indica nombre. Por su trabajo de maestro recibe un salario de 522 reales. También ejerce el oficio de Sacristán, por el que recibe un salario de 180 reales. Su renta total es de 718 reales.

Cirueña, 42. Hay un maestro de niños del que no se indica nombre. Gana 22 fanegas de trigo, la mitad de ellas por repartimiento entre los vecinos y la otra por la propia villa. Los alumnos de Ciriñuela le pagan también 4 fanegas de trigo. Su renta total es de 26 fanegas de trigo, que equivalen a 468 reales.

Castañares de Rioja, 85. No consta.

Castroviejo, 28. No consta.

Cellorigo, 30. No consta.

Cenicero, 250. Pedro Blanco Ruíz. En documento citado en el texto se dice de la escuela que los niños no sacan ningún provecho de ella, y de las enseñanzas de su maestro tampoco, por su "ineptitud y poca habilidad para dicho ejercicio por ser sumamente corto de vista, cuanto por tener otros muchos defectos que le inhabilitan, y lo que más es, la poca asistencia y ningún cuidado que practica en el cumplimiento de su obligación". Por ello se pegarán carteles por los pueblos vecinos buscando un maestro "apto, hábil, y capaz para la enseñanza y educación de los niños". La villa le debe el salario de los años 1748, 1749, y 1750 hasta el San Juan de junio. Los padres le deben 331 reales. Pasado ya su cargo de maestro en la villa se le siguen debiendo los padres 340 reales de vellón, 100 celemines de trigo, y la villa 55 reales de los 400 acordados anualmente.

Pedro San Martín Mena. Casado, hija menor de edad, hijo recién casado, obligación de mantenerlo a este último y su familia hasta San Juan de 1753. También es Criado para el gobierno de las viñas, cobra 6,5 ducados. Salario maestro: 400 reales de la villa y 500 de los niños, también notario apostólico, 50 reales. La villa le da casa valorada en 88 reales. Propiedades: tiene arrendado 600 varas de belezos en sus cubas y un lago de piedra, pagando cada año 126 reales de vellón. 2 cuarterones de pieza que componen media fanega de tierra. 1 pieza hecha 4 partes de las cuales 2 son suyas. 1 pieza que de sus 10 tiene 4,5 celemines de tierra. 10 viñas con un total de 67,5 obradas y 410 cepas. 3 tierras Ilecas con un total de 3,5 fanegas y 10 celemines. Un total de 17,5 fanegas de tierra sin especificar, más 3 obradas y 3 celemines. Olivos: un total de 3 tierras destinadas a olivo con un total de 12 obradas y 4 celemines, con 36 olivos, 22 estacas de olivo y 7 pies de olivo 
viejo. Deudas: 250 ducados de principal y 7,5, corresponden a un año. 140 ducados de principal y 4 debedizos de cada año. 50 ducados de principal y 1,5 debedizos. 40 ducados de principal y 13 debedizos y 7 más de vellón. 25 ducados de principal y 8 reales y 8 más de vellón por cada año. Salario total: 1038 reales.

Miguel de Gamarra. 47 años. Casado. 1 hijo mayor, 18 años, casado, labrador. 300 reales. También Sacristán: 475 reales. Obra pía: 150 reales. En total: 925 reales. 1 casa (72 reales). 85 fanegas de trigo (1530 reales). 4 ovejas y 1 burro ( 25 reales). 13 cabras ( 45,5 reales) y 1 gorrino (30 reales).

Cervera del río Alhama, 641. No consta el nombre. 1890 reales más 110 reales por el mantenimiento de la escuela, total 2000 reales.

Cuzcurrita del río Tirón, 108. Pedro Gaitán y Zárate, perteneciente al Estado Noble, tiene 49 años, está casado, con dos hijos y una hija, menores de edad. Como maestro, la villa le paga 35 fanegas de trigo anuales por repartimiento entre los vecinos, lo que equivaldría a 630 reales. También ejerce como Sacristán, recibiendo por ello 13 fanegas de trigo (234 reales), 6 de cebada (48 reales) 2 de centeno (12 reales) y 20 cántaros de vino (60 reales), pagados por el cabildo. Tiene casa propia. Entre otras posesiones, cita: una cueva, una viña de 20 obreros, viña de dos obreros y medio, viña de cinco obreros, viña de siete obreros, viña de diez obreros, viña de doce obreros, una heredad de tierra blanca de 1 fanega. Se señala que percibe otras 2 fanegas de trigo, pero no se concreta debido a qué.

Cihuri, 35. No consta.

Clavijo, 57. Juan Joseph. Cobra 1.100 reales por todos sus oficios, pues también es organista y sacristán.

Cordovín, 32. No consta.

Corera. No consta. Los niños de esta localidad acuden a Galilea.

Cornago, 249. Maestro, cobra 600 reales de salario.

Daroca del Rioja, 21. No consta.

El Redal, 56. Melchor de Alba, 360 reales (33 reales por familia/niño). 70 reales anuales por campanero. 463 reales.

El Villar de Arnedo, 100. Manuel Viguera. 27 años. Casado, sin hijos. 108 reales más 360 reales pagados por los vecinos. 360 reales anuales por campanero. 828 reales. 11,5 fanegas de trigo (207 reales). 1 viña de 4 peonadas. Vive en una casa del ayuntamiento que le supone un gasto de 4 ducados anuales.

El Villar de Enciso 30. No consta.

Enciso, 187. Consta el gasto de un maestro, pero no se especifica ni sueldo ni nombre.

Entrena, 174. Matheo Gervasio Sánchez. 934 reales. 
Galilea. José García, 9 fanegas de trigo, es además Fiel del pan (6 fanegas), sacristán (6 fanegas) y tocador de campanas (3 fanegas). Salario total: 432 reales.

Gallinero de Cameros, 66. No consta.

Gallinero de Rioja, 15. No consta.

Gimileo, 25. No consta.

Grañón, 200. No consta.

Grávalos, 200. Don Raimundo Calvo, salario de 198 reales y también 288 reales aportados por los niños a los que enseña. También ejerce el oficio de sacristán y campanero por los que recibe un salario de 144 reales. Renta total es de 630 reales.

Haro, 600. Maestro de primeras letras, Juan Antonio Gibaja, 800 reales y la casa (que comparte con el "religioso confesor de esta villa). Hay maestro de gramática, Manuel Matías del Castillo, que cobra 2.000 reales.

Herce, 119. Hay un maestro de niños del que no se indica nombre, salario 913 reales. También ejerce el oficio de organista, pero no se indica el salario que recibe por este oficio.

Laguna de Cameros, 208. Juan de Atance, es además organista y notario apostólico.

Lagunilla de Jubera, 240. Juan de Viguera, del estado noble, de 29 años, casado y con una hija menor, cobra 510 reales como maestro, tiene en propiedad una tierra de secano de $3^{a}$ calidad, viña de secano de 450 cepas, viña de 150 cepas, huerto de 40 frutales, otro huerto de un celemín de sembradura, viña de 76 cepas.

Lardero, 111. José Antonio Ruiz de Gaona, del estado general, de 22 años, viudo y con una hija de temprana edad, cobra 408 reales de la villa y 216 de los niños, además 20 ducados por organista, por sacristán 216 reales, 4 ducados por atender el reloj y por limpiar la ropa de la iglesia 72 reales, vive en casa de Ignacio Clavijo que también le da de comer.

Herramelluri, 60. Bernardino Martínez Neila, casado, perteneciente al estado general y de 26 años de edad. Por su oficio como maestro recibe 684 reales.

Hervías, 49. Simón de la Cámara. Soltero. 20 años.

Hormilla, 104. No consta.

Hormilleja, 28. No consta.

Hornillos de Cameros, 77. Manuel de Soto. Maestro de primeras letras (112 reales) y cirujano (1120 reales). Estado General. Tiene una hija.

Hornos de Moncalvillo, 31. No consta.

Huércanos, 120. Pedro Sáenz Samaniego, maestro de primeras letras, del estado general. Cobra 540 reales, 36 fanegas de trigo. Pechero, casado 
y de edad de 22 años. Tiene una criada, una hija de menor edad y en su compañía a su madre. Mantiene a una muchacha de menor edad para cuidar a su hija, es natural de la villa. Mantiene en su casa a su madre de 76 años. Vive en casa de renta, de Don Juan Franco Martín, presbítero beneficiado de esa villa. Le paga cada año por la casa 3 ducados. También es pesador del grano que se pone en la villa para el molino y recauda por ello 100 reales.

Igea, 471. Juan de Arnedo. Maestro de niños y organista, 1904 reales total. 914 de organista y 990 de maestro.

Inestrillas, 147. No consta.

Jalón de Cameros, 46. Juan Álvarez. Cobra a cada niño media fanega de trigo y una fanega de trigo por leer y escribir. No percibe nada del ayuntamiento.

Jubera, 258. Juan Beltrán del estado general, soltero y de edad de 23 años. Tiene en su compañía una hermana y ninguna familia más, gana 388 reales de Vellón. También es sacristán de la parroquia y gana por ello 153 reales de vellón. Gana 33 reales por el cuidado de gobernar el reloj y 40 reales por tocar a nublado.

Ledesma de la Cogolla, 44. Hay un maestro de niños del que no se indica nombre, recibe un salario de 880 reales.

Leiva, 59. José Villarán. Perteneciente al estado noble, de 30 años, casado, con 2 hijas y un hijo menor de 10 años, recibe un salario de 144 reales. También ejerce el oficio de sacristán por el que recibe 452 reales.

Leza del Río Leza, 97. Juan José Ruiz. Pertenece al Estado Noble, tiene 56 años, y es viudo. Tiene dos hijos, varón y hembra. Es Alcalde de la Hermandad de los Hidalgos. Por maestro y tocar las campanas y por notario percibe una renta total de 750 reales. También se señala que cobra 30 ducados por una obra pía, y como notario apostólico y ordinario una "ganancia accidental y no segura" que calcula en 50 reales al año. Tiene mucha tierra, casa y bodega. Viña de cabida de doscientos treinta leguas, viña de cincuenta cepas de segunda calidad, viña de ciento y treinta cepas de ínfima calidad, viña de 340 cepas de ínfima calidad, viña de mil cepas de mediana calidad, viña de 230 cepas de mediana calidad, viña igual que la anterior. Dos piezas de secano, ocho y quince celemines, una huerta de regadío de cuatro celemines, una alameda, dos cubas de 56 cántaras de vino "bajo la casa que habito", tiene heras y viñas en "renta" de una capellanía (es administrador de esas tierras).

Los Molinos de Ocón. Diego Pisón. Del Estado General, tiene 48 años, está casado, pero no tiene hijos, solamente un entenado que se halla en la ciudad de Logroño estudiando, que se alimenta de limosna "por no poderlo yo mantener, aunque le asisto lo que puedo en vestirlo". Los vecinos le pagan anualmente por la educación de los niños ocho fanegas de trigo (144 rea- 
les). Además, hay que añadir dos fanegas y medio "con que le contribuyen algunos vecinos de los lugares de la comarca por la enseñanza de algunos niños...", es decir, 45 reales. Ejerce también como Sacristán, Fiel de fechos y notario. Por formar las cuentas como fiel de fechos percibe 7 fanegas (126 reales). Por notario 30 reales. Siete fanegas de trigo por sacristán, de ellas, tres las aporta el cabildo eclesiástico y las otras cuatro "del efecto de su práctica". Equivalen a 126 reales. Hace una queja velada de su salario escaso, pues afirma que es "de lo que nos hemos de alimentar, vestir, calzar y pagar médico, boticario y cirujano".

Logroño, 1.614. Gregorio de los Santos. Casado, pechero de 59 años, tiene un hijo y una hija menores. Cobra 730 reales como maestro. Paga renta por una casa y una sala y alcoba y medio pajar en la Villa Nueva.

Andrés Bañares y Valle. Hidalgo no reconocido, aunque luego afirma que "reconocido por noble en esta ciudad". Casado, 28 años, sin hijos. No tiene escuela, por lo que ejerce su oficio en casas particulares, cobrando 440 reales, tanto por maestro como por amanuense de abogado. No paga renta de casa, pero por Navidad "me tiene arrendado un cuarto Santiago Azpillaga en una casa que tiene en venta en la calle mayor por la que pagaré 66 reales de vellón".

Martín Ruiz de Angulo. De estado noble pero no reconocido "por mi imposibilidad y pobreza". Está casado, tiene cuatro hijos, pero solo el menor se encuentra en su "casa y compañía". "No tengo renta fija asignada por mi ejercicio, sino tan solamente lo que me pagan los niños por mi trabajo" Las respuestas le calculan un salario de 912,5 reales. Vive en un cuarto y cocina situado en la Costanilla.

Domingo Fernández de Cenzano. De Estado noble, aunque no reconocido "por falta de medios", viudo de 64 años. Salario: 540 reales. Él, en su memorial, señala: "Tengo en este barrio del Cortijo diez reales de vellón, contingentes por mis salario y trabajo de educar los niños en leer, escribir, cantar y la doctrina cristiana".

Luezas, 53. No consta.

Lumbreras, 360. No consta.

Manjarrés, 28. No consta.

Mansilla de la Sierra, 155. Hay maestro de niños, cobra 1.100 reales.

Manzanares de Rioja, 22. No consta.

Matute, 101. Andrés Gil. Pertenece al estado noble, de 28 años, casado, con tres hijos menores de edad, su madre de 66 años y una criada a la que paga 4 ducados. Por su oficio como maestro recibe un salario de 1552 reales. También ejerce el oficio de organista, pero no se especifica su salario. Hacienda propia, tiene 11 cabezas de ganado, una casa donde da clase y no paga renta (propiedad del pueblo), dos huertas de regadío junto a su casa 
de 2 celemines y 9 tierras secanas de 15, 10, 6, 4, 6, 2, 15, y 20 celemines respectivamente.

Medrano, 57. Hay un maestro de niños, recibe 162 reales. También ejerce el oficio de campanero, por lo que recibe un salario de 96 reales Renta total: 258 reales.

Montalvo, 30. No consta.

Munilla, 293. Juan Francisco Moreno de Tejada. Casado. Tiene un hijo de 18 años. Maestro de primeras letras ( 770 reales), regidor del reloj (110 reales) y fiel de carnicerías (80 reales).

Muro de Aguas, 130. Hay dos maestros, pero no se cita nombre.

Muro de Camero Viejo, 105. No consta.

Murillo de Calahorra, 35. Hay un maestro, no se dice salario.

Murillo de Río Leza, 191. Hay maestro, gana 400 reales.

Nájera, 400. Pedro Lorenzo de Oña. 46 años, casado, con 1 hija menor. 330 reales por maestro. 440 reales por fiel de fechos. Total: 770 reales. Vive en una casa alquilada, la propia de la escuela de Nájera.

Nalda, 237. Antonio de Munilla. Tiene 1 hija. Salario: 342 reales. Propiedad: 1 tierra de sembradura y regadío de media fanega. 1 pieza de tierra de 8 celemines de sembradura y regadío.

Navajún, 210. Consta el salario de un maestro, de 550 reales, pero no se especifica nombre.

Navalsaz, 96. No consta.

Navarrete, 360. José Hernáez Alesón, 31 años, casado, 1 hijo de 3 años y dos hijas de 11 y siete meses. Salario: 600 reales. Cobra a los padres, por el que solo lee: media fanega de trigo. Por el que también escribe y cuenta: 1 fanega de trigo. En total 45 fanegas de trigo. Total renta: 1410 reales. Vive en una casa alquilada a Josefa de Burgos por la que paga 9 ducados anuales.

Nestares, 66. Manuel Bautista de la Muela. Casado, 2 hijos y 2 hijas. Salario maestro: 22 fanegas equivalentes a 330 reales. Casa en renta por la que paga 2 ducados.

Nieva de Cameros, 264. No consta el nombre. Salario maestro: 100 ducados de vellón (1.100 reales). Es también organista, por lo que cobra 20 fanegas de trigo, y por la Casa de misericordia 1 fanega. Salario total: 1478 reales.

Ochanduri, 18. Raimundo del Oyo, Soltero, 29 años, salario maestro: 16 fanegas de pan por mitad de trigo y cebada. También es Sacristán, otras 16 fanegas mitad de trigo y cebada, total: 384 reales.

Ocón, 461 (incluye todas las aldeas del valle de Ocón). Melchor de Alba. 51 años, casado, 2 hijos menores. 1 criada a la que paga 10 reales de vellón. 
Salario maestro: 20 fanegas y 75 reales de censos. Otros oficios: organista; administrador de cuentas; administrador de obras pías. Salario otros oficios: 500 reales y 2 fanegas de trigo; 3 ducados y 3 fanegas de trigo; 12 fanegas de trigo. Casa en renta en la plaza de la Villa, paga anualmente 40 reales. Propiedades: 2 huertas con un total de 1,5 fanegas y una paga de 3 reales. 6 fincas con un total de 17,5 celemines de secano. Otros: 4 censos con 386 ducados de principal y 24046 reales de rédito. Cargas: sobre los censos y otras tierras 27 reales, 4 reales por los servidores. 18 reales por 3 aniversarios. 6 reales por aniversario de la adquisición de una huerta. 6 reales y 4 más para los servidores por el aniversario. 2 fanegas de trigo al cabildo de Santa Eulalia. Salario total: 1.274 reales.

Ojacastro, 178. Manuel del Corral, del estado general, de 40 años, casado y con dos hijos menores, cobra 40 fanegas de centeno como maestro (500 reales).

Ollauri, 76. José Pérez de Villavezana, del estado indiferente (sic), de 31 años y casado, cobra 70 cántaras de vino como maestro y 4 fanegas de trigo por atender el reloj y 6,5 fanegas de trigo y 20 cantaras de vino por sacristán (tiene que poner el vino en las misas), vive en un cuarto de la casa de la villa.

Ortigosa, 420. No consta nombre. Cobra 1300 reales como maestro y organista.

Pajares, aldea de Lumbreras. Juan Benito Eraso, del estado noble, 63 años y casado, residen con él una hija y dos nietas, cobra 1800 reales como maestro y organista, vive en una casa a renta en Lumbreras.

Pipaona, aldea de Ocón. Maestro de primeras letras Diego Carrillo, morador en dicha villa, de 58 años, de estado general y casado, con un hijo de 18 años que está estudiando. Le pagan por la asistencia a los niños y su educación 10 fanegas de trigo. También toca las campanas y es sacristán de la parroquial de Pipaona, por esos trabajos le pagan los vecinos 4 fanegas de trigo y el cabildo 2, también cobra cada año por los efectos del común de dicho lugar 6 fanegas de trigo por formar las cuentas.

Pradillo, 90. José Sorzano, maestro de niños y cirujano y sangrador. Le pagan por maestro 350 reales los padres de los niños a los que da clase, de cirujano le pagan por repartimiento entre los vecinos 1550 reales y libre de renta la casa en que vive. Está casado, pechero de 34 años, tiene 3 hijos menores y 3 hijas, todos menores de edad. Tiene una criada en casa para los trabajos del hogar a la que paga 9 ducados al año. Tiene 2 cerdos para el consumo de casa. Tiene en la salida de la villa un huerto a renta de Juan Antonio, tierra de primera suerte que tiene un cuartillo de sembradura. Paga por él 4 reales al dicho Juan Antonio.

Préjano, 122. No consta.

Quel, 338. Joachín Sáenz casado del estado general, maestro de primeras letras. Tiene un $i$ ? De menor edad y no más familia. Tiene una pieza de tierra de sembradura de regadío que contiene una fanega con 4 olivos de segunda 
calidad, la tierra es de la segunda calidad de su especie. Otra pieza de tierra de sembradura de regadío que contiene 2 celemines, de la segunda calidad. Otra tierra de sembradura de regadío que contiene 6 celemines de la tercera calidad. Una pieza de sembradura de secano contiene fanega y media de la tercera calidad. Una viña de secano contiene 9 celemines, de la primera calidad. Otra viña contiene 6 celemines, de la primera calidad. Otra viña que contiene 9 celemines, de la segunda calidad. Otra viña que contiene 9 celemines de la segunda calidad. Otra viña con 10 celemines de la tercera calidad. Otra viña con 7 celemines de la tercera calidad. Una pieza de tierra inculta que contiene fanega y media, de la primera calidad. Tiene 100 cantaras de cubamento en bodegas de Franco Saenz que su alquiler se regula al año en 17 reales y 22 maravedís. Tiene contra sus bienes la carga de un censo de 183 reales y 11 maravedís de capital al quitar, a favor de la obra pía de Ozaeta, por cuyos reductos al 3 por ciento paga en cada año 5 reales y 16 maravedís. En el arrendamiento eclesiástico perteneciente a la obra pía le queda de utilizad al año bajada la renta, 45 reales y 25 maravedís. Por la educación de los niños contribuye la obra pía con 220 reales. Por maestro se le considera de utilidad al año 396 reales.

Rabanera, 68. Pedro Iñiguez Martínez. Salario maestro: 150 reales. Otros oficios: sacristán; fiel de pan; tocar las campanas. Salario otros oficios: 6 fanegas de trigo; 5 fanegas; 5 fanegas. Salario total: 438 reales.

Ribafrecha, 240. Carlos de Soto, pechero, casado de edad de 46 años maestro de niños y sacristán. Tiene un hijo y 3 hijas menores y mantiene a su padre de 80 años. Gana por maestro 10 fanegas de trigo y de sacristán 3 fanegas y 4 ducados, de ese salario de sacristán se gasta todo en el mantenimiento de la casa. Tiene una burra que le sirve para la labranza y tiene 4 cabras. Tiene una viña de primera calidad. Otra viña de 300 cepas de mediana calidad. Tiene otra viña de 450 cepas de buena calidad. Otra de 300 cepas de mediana calidad. Otra de 150 cepas de ínfima calidad. Otra de 200 cepas de ínfima calidad. De viñas a secano tiene, una viña de 100 cepas de ínfima calidad. Otra viña de 200 cepas de ínfima calidad.

Domingo Sáenz de Miguel 263 reales. Pechero, casado, de edad de 64 años, tiene un hijo de menor edad. Percibe 13 fanegas de trigo de los niños que escriben. Por el reloj le pagan 44 reales. Tiene una casa, que no habita nadie en ella por lo mal tratada que está. Tiene una casa en renta.

Rincón de Soto, 197. Maestro Manuel Ruiz de Velasco. Percibe como maestro media fanega de trigo que importan 8 reales. En cada año 21 fanegas de trigo por sus discípulos. 228 reales de dinero que le dan ayuda de costa esta villa y las cofradías de San Miguel, San Pedro, La Asunción y la capellanía de nuestra Señora de Carroviello. Poseía una finca de regadío que producía todos años años. Otra finca que llamaba "Pieza de la presa", contiene 4 zelemines ( $1 / 4$ de fanega) y 3 quartillos con dos árboles frutales de $1^{\text {a }}$ calidad. 
Otra finca de regadío que contiene una fanega y dos zelemines, de $3^{\text {a }}$ calidad. Otra finca que contiene dos fanegas y media, de $3^{\text {a }}$ calidad de su especie.Otra finca de viñas de media fanega mas dos árboles frutales de $1^{\text {a }} \mathrm{ca}-$ lidad. Otra finca de viñedo que contiene 9 zelemines y medio con un árbol frutal de la $1^{a}$ calidad. Una casa con cuarto bajo principal, desván y corral. La alquila al año en 66 reales de vellón. Como salario recibe cada año 568 reales más tres árboles frutales de $1^{\mathrm{a}}$ calidad, 78 olivos de $1^{\mathrm{a}}$ calidad que importa al año 37 reales de vellón.

Robles del Castillo, 110. No consta.

Rodezno, 20. No consta.

Sajazarra, 51. Pedro Martínez. Por tocar las campanas y la enseñanza de los niños doce fanegas de trigo (96 reales), un cordero (9 reales), una lana que se regula por tres libras y diez cántaros de vino (30 reales), que todo vale 540 reales. Percibe del salario del común 4 fanegas de trigo y tres de cebada.

San Asensio, 212. Bernardo de la Puebla, del Estado general, tiene 44 años, está casado con dos hijos, además de mantener una criada. 300 reales anuales le da la villa por maestro de niños además de las 50 fanegas de trigo que se reparten por la enseñanza de los hijos de vecino (900 reales). Entre otras propiedades: 1 fanega de tierra de secano de tercera calidad. Media fanega de tierra de secano de tercera calidad. Dos fanegas y medio de secano de tercera calidad. Tiene una de las cuatro escribanías.

San Millán de la Cogolla, 300. Domingo Torrano. Casado, 62 años, 2 hijos. Salario maestro: 1165 reales. Propiedades: casa en la medra con solar, corral, cocina, y caballeriza. 5 heredades que hacen un total de 10 fanegas y 18 celemines. Ganado: 1 cerdo de cría y 2 cabras. 4 nogales, otros 16 árboles de ciruelas y 8 fanegas de trigo. 1 solar en San Roque. Salario total: 1165 reales.

San Millán de Yécora, 41. Francisco Muñoz. 47 años, casado, 4 hijos. Salario maestro: 15 fanegas de trigo equivalentes a 240 reales. Otros oficios: fiel de hechos (32 reales); tocar las campanas (112); sacristán (160 reales). Salario total: 616 reales.

San Román de Cameros, 150. Agustín Saenz, del estado general, tiene una hija.

San Torcuato, 36. No consta.

San Vicente de la Sonsierra, 310. No consta nombre, salario 550 reales.

Santa Coloma, 51. José Villar Baños. Hidalgo, aunque no en posesión. De edad de 32 años, tiene tres hijos menores de edad y un criado, que tiene 15 años, a quien hace de soldada al año y se encarga de su almuerzo diario, además de destinar 90 reales en su vestido, calzado y recado necesario para la escuela. Cobra 14 fanegas de trigo por maestro (252 reales). Por campanero y tocar el reloj 12 fanegas de trigo (216 reales). Por sacristán y organista 330 reales y por el de posador 65 reales. 
Santa Lucia, aldea de Ocón. Miguel Cruz Martínez. Salario maestro: 20 fanegas. También Sacristán, 10 fanegas y 44 reales. Salario total: 584 reales.

Santa María de Cameros, 38. No consta.

Santo Domingo de la Calzada, 450. Manuel de Suso, 65 años, casado y con dos hijos, cobra 1100 reales de la villa y 600 de los niños, vive en la casa de la villa y no tiene bienes.

Santurde, 92. No consta.

Santurdejo, 73. No consta.

Sojuela, 44. José Gil. Cobra por ser maestro 8 fanegas y 112 reales. Su renta total es de 256 reales.

Sorzano, 63. Miguel Martínez. Tiene 1 hijo menor de 18 años y 3 hijas más. Como maestro cobra 170 reales. También sacristán, 194 reales, y por tocar las campanas 50 reales. Su renta total es de 414 reales

Sotés, 63. Francisco Fernández, maestro de niños. Está casado, tiene 40 años y un hijo y una hija, ambos menos de edad. También tiene una criada. Por su conducción le paga esta villa 12 fanegas de trigo que se reparten a los padres de los niños. También hace oficio de sacristán y campanero, por lo que percibe del cabildo eclesiástico de esta villa 12 fanegas de trigo, 12 de centeno y 30 cántaras de vino tinto, y por ello suple la obligación para esta iglesia. 5 fanegas de trigo por tocar las campanas a nublado, 3 fanegas de trigo que percibe dicha villa y de las fábricas de su iglesia por mitad todo anualmente.

Soto en Cameros, 545. Tres maestros de la misma familia, uno de ellos preceptor de Gramática. Francisco Javier Cabezón, preceptor, cobra 408 reales que le pagan los padres de los niños. A Francisco Cabezón, maestro, el pueblo le paga 300 reales y 360 los padres, 660 en total. Domingo Cabezón cobra 162 de una aldea, 360 de los padres y 7 fanegas de trigo por sacristán y 4 por tocar las campanas. En total 720 reales.

Terroba, 42. No consta.

Tobia, 23. No consta.

Tormantos, 62. Juan Bautista Crespo, 36 años, del estado noble, está casado con Juana Pastor y tiene dos hijas. Recibe por su oficio como maestro un salario de 936 reales.

Torre en Cameros, 65. No consta.

Torrecilla en Cameros, 400. Diego Antonio Solana, percibe de salario 1.140, además "se le ha considerado de utilidad con los chicos 360 reales".

Torrecilla sobre Alesanco, 73. No consta.

Torremuña, 103. No consta.

Treviana, 111. No consta. 
Trevijano, 60. No consta.

Tricio, 90. Manuel Muro, del estado general, de 27 años y soltero. Por su oficio como maestro recibe 576 reales.

Tudelilla, 169. No consta.

Turruncún, 50. Maestro Ambrosio de la Cosería. Casado, con un hijo menor de edad y una hija. Además de maestro es cirujano por lo que percibe 51 fanegas de trigo más 50 cántaras de mosto. Por Sacristán le da la fábrica de dicha parroquia 8 ducados y el común del lugar 44 reales más 25 reales para la renta de su casa. Como maestro percibe 9 ducados al año (99 reales).

Uruñuela, 85. Hay un maestro, no consta nombre.

Valgañón, 140. No consta.

Ventosa, 109. Juan Andrés Picazarri casado, de estado noble, de 35 años. Tiene un hijo de 6 años y mantiene un sobrino huérfano y tiene también una hija de 11 años y un criado. Es maestro de niños, organista y sacristán. Examinado y aprobado por el supremo consejo de Castilla. Tiene de salario de la villa y del cabildo 60 fanegas de trigo y 164 reales en dinero. Para los cuales tengo de carga 60 reales y 80 reales que pago de renta de la casa a María Herrera cuya casa está en el barrio demedio.

Ventrosa, 143. Miguel García Moreno López, viudo, de estado noble maestro de niños que tiene dos hijas. Tiene una pieza de tierra de hortaliza con el regadío a brazo, contiene un cuartillo es de única calidad. Tiene una pieza de tierra de secano que dista de la población 300 pasos y contiene 4 celemines de segunda calidad. Otra pieza de tierra que dista de la población medio cuarto de legua y contiene 3 celemines de segunda calidad de su especie. Una pieza de tierra de secano que dista de la población media legua y contiene 7 celemines de tercera calidad. Otra pieza de tierra que dista media legua de la población y contiene 3 celemines de tercera calidad. Otra pieza que dista una legua larga de la población y contiene 7 celemines de tercera calidad. Otra pieza que dista una legua de la población y contiene 3 celemines de tercera calidad. Otra pieza que dista legua y media y contiene 3 celemines de la tercera calidad. Tiene una casa de habitación en el barrio de Heras con cuarto en alto y desvanes. Es maestro de primeras letras y percibe de salario 300 reales anuales. Tiene pastando en la Extremadura en invierno 29 ovejas 10 corderos y 7 carneros y en la villa todo el año, 5 ovejas churras. El esquilo de la partida anterior importa 411 reales y medio. Además de dicho esquilmo se utiliza de 68 reales en el ganado que de su piara vende.

Viguera, 257. Maestro, salario 1.853 reales. No da el nombre.

Viniegra de abajo, 131. Joseph Matanza, casado del estado general, no tiene familia alguna. Residente en Viniegra de abajo, tiene una tierra de secano que dista de la población a cuarto de legua y contiene 3 celemines de tercera 
calidad de su especie. Maestro de niños que gana 446 reales y es de su cargo el régimen del reloj. (0027)

Viniegra de arriba, 89. Maestro de niños, salario 250 reales.

Villamediana, 196. No consta, pero hay maestro de niños.

Villar de Torre, 57. Maestro: 26 fanegas de trigo por maestro, también sacristán, 13 fanegas y media de trigo y dos de cebada, y 30 reales por cuidar el reloj. Total: 686 reales.

Villarejo, 22. No consta nombre. Salario: 342 reales (19 fanegas de trigo).

Villarroya, 40. Un cirujano llamado Joseph Garijo, 25 años, está casado, y pertenece al estado general. No tiene hijos. Vive en casa del cabildo, y por ello paga 30 reales. "...Que de continuo reside en este pueblo asalariado con sus vecinos para asistirles a cuanto corresponde a su oficio, de quienes anualmente cobra por su trabajo y salario 40 fanegas de morcajo al mismo respecto; que también ejerce el susodicho en este lugar el empleo de maestro de primeras letras, y el de fiel de fechos, por cuyo trabajo se le pagan por dichos vecinos anualmente cien reales de vellón en dinero, y cuarenta en el valor de cuarenta fanegas de leña, que le conceden a su casa, también se ejercita en asistir por sacristán en la parroquia de este lugar, y tocar las campanas a cuantas funciones se ofrecen y nublado y por el trabajo de uno y otro se le pagan en cada año por los vecinos de este lugar y por la fábrica de esta Parroquia diez fanegas de morcajo".

Villarta Quintana, 54. Gabriel Pérez, clérigo de prima y grados, capellán de la capellanía de esta villa, 40 años de edad, tiene dos muchachas de servicio, una para su asistencia, a la que paga doce ducados de soldada, y otra para el trabajo de su casa, a la que paga 30 reales de soldada. Gana por el ejercicio de maestro de primeras letras 15 fanegas de trigo al año y por tocar las campanas a nublado en tiempo de tempestades también tres fanegas de trigo. Tiene una yegua, con sus crías al pie; tres cabras; un chivato; $y$ "dos prímalos de dicho ganado cabrío", cuatro crías de cerda, una de ellas de cuchillo. Tiene "en esta villa dos partes de una casa".

Villavelayo, 82. No consta.

Villaverde de Rioja, 35. Javier de Chorrutia. 45 años, viudo, 3 hijos, dos menores y uno de 19 años viviendo en Bobadilla. Salario de maestro: 702 reales. También Cirujano, no se especifica la retribución ya que está dentro de los 702 reales que cobra del ayuntamiento. Cobra 19 ducados de renta de unas fanegas que tiene. No dispone de casa, ya que se encuentra de balde en la casa del maestro, cedida por la villa. Tiene 3 cerdas y 1 cerdo, para consumo propio y venta.

Villoslada de Cameros, 310. Francisco Bazo Ibañez. 1 hijo, estado viudo en segundas nupcias. Salario: 700 reales y 40 reales por niño cuando puedan pagarlos. También es Notario, por lo que recibe 30 reales. Total: 1200 reales. 
No dispone de casa, ya que se encuentra de balde en la casa del maestro, cedida por la villa. Se queja insistentemente de la falta de niños en la escuela, a causa de tener que trabajar en el campo o por los caminos bloqueados por la nieve o por las lluvias.

Zarratón, 47. No consta.

Zarzosa, 125. Maestro de niños, Francisco Hogazón, 450 reales. Pertenece al Estado General, tiene una hija sin más familia. No tiene otros bienes.

Zorraquín, 23. No consta. 